\title{
Diálogos Acadêmicos: A cooperação internacional entre a França e o Brasil em territórios amazônicos. Entrevista com o Prof. François- Michel Le Tourneau, Geógrafo, Diretor de Pesquisa no Centro Nacional de Pesquisa Científica (CNRS), e no Institut des Hautes Études de l'Amérique Latine (IHEAL) da Sorbonne-Nouvelle (Universidade de Paris 3)
}

\section{Luciana Riça Mourão Borges'}

1 Doutoranda e Mestre pelo Programa de Pós-Graduação em Geografia Humana da Faculdade de Filosofia, Letras e Ciências Humanas da Universidade de São Paulo (PPGH/FFLCH/USP), Licenciada e Bacharel pela Universidade Federal de Rondônia (UNIR), Brasil. E-mail: lu.rmborges@gmail.com

RESUMO: A entrevista aqui apresentada foi concedida pelo Professor Doutor FrançoisMichel Le Tourneau, com o objetivo de apresentar aos leitores um pouco da experiência de cooperação acadêmica internacional entre o Brasil e a França, no âmbito de pesquisas desenvolvidas na Amazônia. Pude elaborar esse material por ocasião da realização do meu doutorado sanduíche no Institut des Hautes Études de l'Amérique Latine (IHEAL/CREDA), no período de setembro de 2015 a agosto de 2016, do qual o Prof. FrançoisMichel faz parte. Serão relatadas, principalmente, sua trajetória acadêmica, seus trabaIhos, projetos, atuação em pesquisas na Amazônia e projeções para a continuidade da cooperação acadêmica internacional entre os dois países.

Dialogues Academic: International cooperation between France and Brazil in Amazon territories. Interview with Prof. François-Michel Le Tourneau, Geographer, Director of

Research at the National Center for Scientific Research (CNRS) and the Institut des Hautes Etudes de l'Amérique Latine (IHEAL) at Sorbonne-Nouvelle

\begin{abstract}
The interview presented here was given by Professor François-Michel Le Tourneau, with the aim of presenting to readers some of the international academic experience of cooperation between Brazil and France, as part of research carried out in the Amazon region in Brazil. I could prepare the material on the occasion of my sandwich doctorate at the Institut des Hautes Etudes de l'Amérique Latine (IHEAL/CREDA), from September 2015 to August 2016, in which Prof. François-Michel is part of. Will be reported his academic career, his works, projects, research activities in the Amazon and projections for continued international academic cooperation between these two countries.
\end{abstract}

Esta entrevista tem como objetivo apresentar aos leitores um pouco da experiência de cooperação acadêmica internacional entre o Brasil e a França, voltada principalmente para a área de pesquisa, a partir da circulação de docentes, pesquisadores e pós-graduandos em ambos os territórios. O foco se dá, sobretudo, em pesquisas desenvolvidas por franceses na Amazônia e a abertura das instituições francesas para o recebimento de brasileiros amazônidas nos seus centros de pesquisa. Para tanto, contatei o Professor Doutor François-Michel Le Tourneau, geógrafo com uma larga 
experiência em temas como Amazônia, Geografia Política, Cartografia, Meio Ambiente, Sustentabilidade e América Latina, para nos relatar um pouco sobre sua trajetória, seus projetos, a participação em pesquisas na Amazônia, bem como a cooperação internacional e o intercâmbio de alunos e docentes entre Brasil e França.

Esse material pôde ser elaborado a partir da minha própria experiência de intercâmbio, realizada entre setembro de 2015 e agosto de 2016, pelo Programa de Doutorado Sanduíche no Exterior da CAPES, no qual pude vivenciar as experiências aqui relatadas, dentro dos institutos de pesquisa relacionados. O Professor FrançoisMichel me recebeu em seu instituto para o desenvolvimento de parte de minha tese de doutorado, e gentilmente nos concedeu essa entrevista.

François-Michel Le Tourneau é atualmente diretor de pesquisa do Centre National de La Recherche Scientifique (CNRS), instituição de fomento à pesquisa científica na França, bem como é membro, docente e pesquisador do Institut des Hautes Études de l'Amérique Latine (IHEAL) e do Institut des Amériques (IDA), ambos pertencentes ao Centre de Recherche et de Documentation sur les Amériques, da Université de Paris 3 (Sorbonne-Nouvelle). Também é coordenador do Projeto Duramaz, que tem como principal objetivo estudar e analisar treze experiências de atividades sustentáveis na Amazônia, a partir da coleta e sistematização de um grande banco de dados geográficos e estatísticos, contribuindo, assim, para um conhecimento ainda mais amplo de diversas realidades amazônicas.

Reforçando as já sólidas parcerias entre o Brasil e a França no campo acadêmico, e com intuito de motivar ainda mais os intercâmbios futuros, dou a palavra ao Professor François-Michel.

Luciana Borges: Considerando sua vasta experiência acadêmica tanto na França, quanto no Brasil, o senhor poderia nos relatar um pouco da sua trajetória durante sua formação, sua atuação na Universidade de Paris 3, e como se deu o seu interesse pela Amazônia através de suas pesquisas na área de geografia?

François-Michel Le Tourneau: Entrei na Ecole Normale Supérieure em 1993 e me graduei em história e geografia em La Sorbonne. Comecei a me especializar na área de informação geográfica e de SIG. Acontece que na época imagens de sensoriamento remoto eram raras e preciosas. Trabalhava-se bastante em função do material disponível. Tinha um jogo interessante de imagens ERS-1 e ERS-2 da Amazônia, por isso comecei a me interessar por essa região. Rapidamente me apaixonei pela Amazônia e sua gente, e decidi me especializar sobre tal área. Achava a velocidade das mudanças em curso realmente fascinante. Depois comecei a conhecer os povos da floresta e me interessei mais aos modos de vidas nas áreas florestais, com um enfoque mais voltado à geografia humana, apesar de manter um pé nos SIG.

Luciana Borges: Quais foram os seus principais trabalhos realizados sobre a região 
amazônica?

François-Michel Le Tourneau: Trabalhei bastante junto a populações indígenas, especialmente aos Yanomami. Escrevi um livro sobre o território e a geografia dessa etnia. Também me dediquei ao estudo da sustentabilidade de diversas situações na Amazônia no âmbito do programa de pesquisa DURAMAZ, que teve duas fases (20072011 e 2012-2015). Este foi muito importante pois permitiu de trabalhar em áreas muito diversas da Amazônia do ponto de vista social, econômico, ecológico. Ultimamente, também passei bastante tempo estudando a área fronteiriça entre o Brasil e a Guiana francesa, onde montei diversas expedições (a pé, de canoa, etc.) para reexplorar lugares que hoje são totalmente desertos. Com parte desse material, escrevi um livro sobre o rio Jari.

Luciana Borges: Nos últimos anos temos percebido um grande avanço em termos de ferramentas diversas utilizadas no meio acadêmico, entre elas a informática e a possibilidade de geração de informações e dados sobre um determinado campo do conhecimento de modo muito dinâmico. Como o senhor vê a relação entre a ciência e a tecnologia dentro da Geografia hoje, e de que forma isso pode influenciar nas pesquisas realizadas na Amazônia?

François-Michel Le Tourneau: De fato o quadro mudou, muito mais ainda se a gente comparar com os anos 1990 ou 1980. Antigamente, o dado em si era objeto de pesquisa, nem tudo mundo conseguia ter acesso às estatísticas, muito menos a dados geográficos. Mostrar estes, montar mapas, aquilo era a tarefa básica dos geógrafos, assim como propôr uma interpretação destes. Hoje em dia houve um duplo movimento que deu acesso muito mais fácil aos dados assim como às ferramentas para tratá-los. O grande público pode montar os mesmos mapas do que geógrafos especializados. Assim sendo, do meu ponto de vista, a parte técnica da profissão de geógrafo talvez esteja hoje menos importante, e a parte interpretativa maior. Tudo mundo pode fazer mapas ou ler estatísticas, mas aquilo não implica no fato de que tudo mundo faça mapas bons ou oportunos, e que as conclusões que tiram sejam legítimas. A partir de um conhecimento íntimo das áreas sobre as quais ele trabalha, e tendo uma boa formação metodológica, o geógrafo contemporêano pode propôr interpretações mais justas e úteis à sociedade. Por outro lado há novas ferramentas que ainda precisam de alta perícia técnica para serem usadas (funções avançadas de sensoriamento remoto e análise complexa dos dados). Em relação à Amazônia, o que mudou é a relação com o desconhecido. Antigamente a Amazônia era em grande parte um mistério, uma área sobre a qual faltavam informações. Hoje em dia, apesar de dificuldades ligadas ao clima, ao afastamento, etc., nós temos uma visão bastante detalhada do espaço amazônico. Mostrar este conhecimento, confrontá-lo com os clichês que muita gente continua tendo sobre a região e testar os seus limites (por 
exemplo, analisar o que acontece debaixo da cobertura florestal mas não fica aparente aos "olhos" dos satélites bem como as motivações das populações que explicam as transformações em curso), isto é para mim o trabalho dos geógrafos de hoje.

Luciana Borges: O senhor poderia nos falar um pouco sobre o Projeto DURAMAZ e quais têm sido os principais resultados vistos nesses anos de intensas pesquisas e trabalho de campo?

François-Michel Le Tourneau: O projeto DURAMAZ tem como príncipio a comparação de diversas áreas de estudo espalhadas na Amazônia brasileira e correspondentes ao leque de situaçãos encontradas na região. Os 13 "sítios" são comunidades ou pequenas localidades que foram intensamente estudadas durante as duas fases (2007-2011 e 2012-2015). No início do projeto, o foco era mais sobre a avaliação da sustentabilidade em cada um. Um sistema de indicadores foi desenvolvido para tal fim. A segunda etapa buscou mais retratar as intensas mudanças pelas quais a região passou durante a última década. A Amazônia conectou-se de maneira rápida ao resto do país, em especial do ponto de vista econômico. Vê-se que hoje em dia até populações ditas "isoladas" são incluídas na economia monetária, nas redes socias. Aquilo implica em mudanças de estilo de vida e estamos tentando entender as consequências dessa grande mudança.

Luciana Borges: Considerando o grande intercâmbio entre franceses e brasileiros tanto nas universidades da França, quanto nas do Brasil, e também pela experiência do DURAMAZ, além dos diversos trabalhos de teses e dissertações, frutos de toda essa troca acadêmica que existe em âmbito da Universidade de Paris 3, como o senhor avalia essa intensa participação de ambas as partes?

François-Michel Le Tourneau: Aqui também o quadro é de mudança. Há vinte anos atrás os Brasileiros vinham para a França para cursar o doutorado, buscando formação e conhecimento que pouco tinha no Brasil. Hoje em dias as universidades cresceram muito no Brasil assim como o nível acadêmico elevou-se, se bem que estamos muito mais numa relação de cooperação de igual a igual (quando as condições de trabalho no Brasil não superam as que temos na França, o que também acontece). Ainda assim há espaço para continuar a trabalhar juntos pois o olhar dos Franceses sobre o Brasil é diferente do olhar dos Brasileiros, e assim, deslocando o foco, acho que podemos trazer benefícios aos nossos colegas. Permanece uma assimetria: vários geógrafos franceses estudam o Brasil com colegas brasileiros, mas poucos Brasileiros estudam a geografia da França, o que considero uma pena. Claro que a França possui uma tradição enciclopédica que nem todo país compartilha. Ainda assim o Brasil continua focalizado sobre si mesmo, ao que me parece, e acho que no estudo de outras realidades ele poderia derivar outros tipos de conhecimento que, no final, ajudariam 
a entender ou relativizar fenômenos que por enquanto são vistos como tipicamente brasileiros. A questão do desmatamento, por exemplo, poderia ser enriquecida com trabalhos sobre a Indonesia, a questão agrícola com estudos sobre a reorganização do setor agropecuário na França nas últimas décadas, etc.

Luciana Borges: E como o senhor avalia os incentivos dos dois governos (França $e$ Brasil) para o aperfeiçoamento no nível superior, ou seja, a pós-graduação, e a realização de incentivos à pesquisa, como bolsas de estudos para mestrado, doutorado e pós-doutorado?

François-Michel Le Tourneau: Até pouco tempo atrás, diria que o Brasil cumpria muito bem a sua parte, e bem melhor do que a França. Os diversos programas de fortalecimento do ensino superior davam bastante incentivo para quem queria fazer um doutorado no exterior (pleno ou sanduich) e havia até possibilidade de viajar na graduação - mesmo que mais usada para cursar ciências nos EUA. A crise com certeza está tornando as coisas mais difíceis. Da mesma forma havia muita vaga para os recém-formados nas universidades federais devido ao crescimento destas no Brasil. Do lado francês, estamos numa crise de financiamento há décadas. Conseguimos bolsas para os nossos estudantes às duras penas, e fica quase impossível achar uma bolsa francesa para um estudante brasileiro. É uma grande pena pois atraír os estudantes de doutorado é provavelmente a melhor forma de manter algum tipo de influência diplomática no futuro.

Luciana Borges: Quais as principais dificuldades encontradas e observadas nesse intercâmbio entre o Brasil e a França, de ambas as partes, para a realização das atividades de pesquisa e para o avanço da ciência e tecnologia, considerando a experiência da Univ. de Paris 3?

François-Michel Le Tourneau: Não estou bem colocado para falar das dificuldades dos Brasileiros para estudarem ou pesquisarem na França. Apesar das restrições que acabei de mencionar sobre as bolsas, me parece que as coisas são bastante abertas, em especial nunca ouvi falar de dificuldades em relação aos objetos de pesquisa. Um pesquisador brasileiro poderá trabalhar em qualquer parte do território francês e junto a qualquer tipo de população sem que haja restrição. Já no Brasil a situação é um pouco diferente. Existem umas regras para pesquisar em áreas indígenas ou unidades de conservação, por exemplo, que na prática inviabilizam tais tentativas. Muitas vezes essas regras não diferenciam as ciências sociais das demais, o que resulta em situações esquisitas. Assim, um turista pode falar com um residente da RDS Mamirauá da sua renda sem que isto seja problema, mas, enquanto pesquisador, eu não posso fazer este tipo de pergunta sem autorização pois são "populações tradicionais" e preciso primeiro pedir licença a diversos órgãos. Acho que o Brasil precisa superar o 
que chamo de "paradigma da biopirataria" e não desconfiar a priori dos pesquisadores estrangeiros. Casos de abuso existem, mas são raros no final (muito mais ainda na área de ciência social onde não se toma nada de concreto), e o benefício que o Brasil poderia retirar dos conhecimentos gerados sobre o seu território e a sua população por pesquisadores estrangeiros talvez vala mais do que o que ele poderia perder com estes pesquisadores mal-intencionados.

Luciana Borges: Como funcionam o Institut des Amériques e o CREDA, em termos tanto de recepção de alunos do Brasil quanto para o envio de alunos franceses, principalmente os que estão mais envolvidos com a temática de Amazônia?

François-Michel Le Tourneau: Em termos de recepção, podemos receber alunos de pós-graduação em qualquer modalidade, desde curtas estadias de pesquisa até doutorado pleno no exterior. Depende muito do aluno e do seu projeto. Temos convênios com muitas universidades federais e podemos concluir outros se for necessário. Em termos de envio de estudantes, temos convênios com umas universidades para que os nossos estudantes passem semestres no Brasil. Na pós, o que usamos mais agora é a formula de "cotutela" na qual duas universidades, uma na França e outra no Brasil, se agrupam para formar um estudante de doutorado. No final, este defende um só doutorado mas acaba com o título de doutor em cada uma das universidades. Aliás tal modalidade também é bastante usada para receber alunos do Brasil, especialmente na modalidade "sandwich". A Amazônia é uma área que atrai alguns estudantes franceses, mas não mais do que outras partes do Brasil. São os interesses dos alunos que definem sua trajetória. Os que me procuram aqui em geral têm interesse pelos temas da Amazônia e sabem que estou especializado sobre aquela região.

Luciana Borges: Quais as perspectivas de parcerias ou continuidade dos trabalhos atuais para o futuro, visando essa cooperação internacional e contribuição, no campo da Geografia, principalmente, para o avanço das áreas do conhecimento, bem como para a sociedade como um todo?

François-Michel Le Tourneau: Acho que a cooperação hoje em dia se faz bastante em torno de projetos de 3-4 anos financiados pelas agências de fomento à pesquisa. Ao mesmo tempo aquilo é uma força (pois se emplacar um projeto, você consegue os meios para realizar uma boa pesquisa por um prazo) e uma vulnerabilidade (pois a cada 3-4 anos você precisa propôr um novo projeto e em função do contexto econômico é possível de não conseguir por certo tempo, tirando toda continuidade às ações de pesquisa). Em termos de temáticas e avanços para a sociedade, acho que a análise das mudanças da região amazônica e das suas populações continua um tema muito rico. Tais mudanças não são uniformes, elas incorporam avanços e retrocessos, e devem ser colocadas em perspectiva com as questões ambiental e climática. Ainda 
temos muito trabalho na nossa frente para dar conta da diversidade amazônica!

Entrevista recebida em 10 de agosto de 2017.

Aprovado em 14 de agosto de 2017. 